\title{
Lepton Pair Production and the Modified Dre11-Yan Mechanism in High Energy Unpolarized and Polarized pp and $\bar{p} p$ Collisions
}

Chih Kwan Chen

NOTICE

PORTINNS OF TIT EEPRT ARE ITIESTESE It has bsen reprocide a f'rcm t:ae best avajlable ; copy to permit the brocdestpossible availability. 


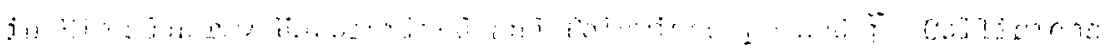

\author{
Q B.:

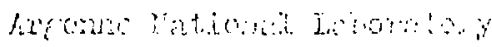

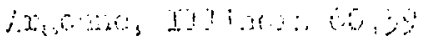 \\ $(30,3,10 \%)$
}

Abstract

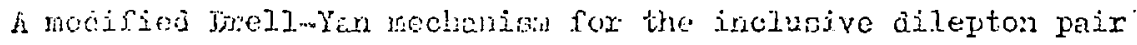
production in hecronic reactions is studied, and the sirnificance of conpaune hith oneroy unpolarized and polaxized jp and $\vec{p}$ polljsions

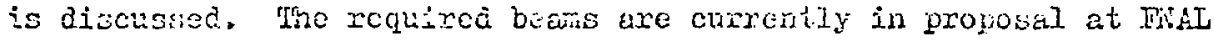
and $\mathrm{CEIN}$.

*Work done under the auspices of the U. S. Juesgy Research and Devejopnent sirinistrition. 


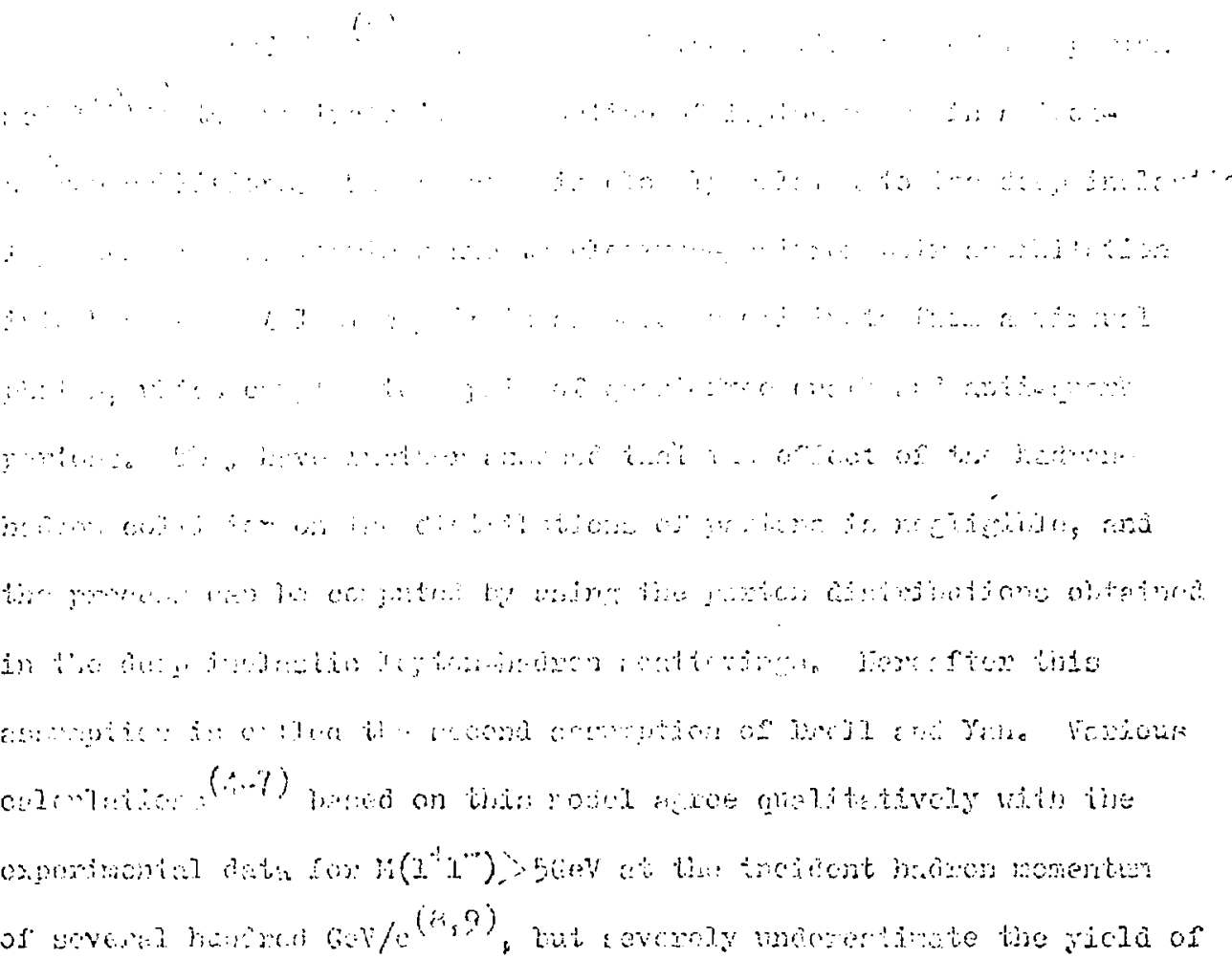

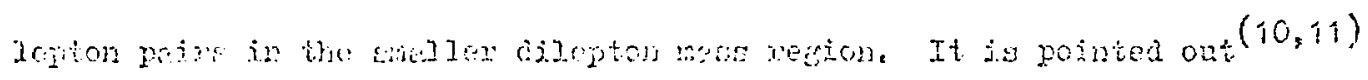

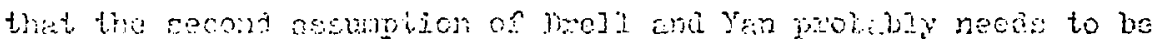

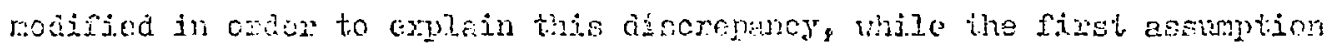

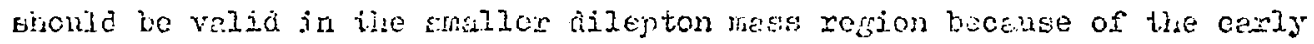
Bjolien scaling (3) observed in the deep inelastic zeptonwuciteon scatterine processes and the behevior of the ratio $R$ of eloctron-positron pair annihilation into hedrons. The purpose of this letter is to investigate ruch a modified Drell-Yan mechanism in detail, and study its implication and the significance of comparing the high enerty uppolarized $\mathrm{pp}$ and $\overline{\mathrm{p}} \mathrm{p}$, and polarized $\mathrm{pp}$ ard $\mathrm{p} \mathrm{p}$ collisions. The construction of the hich enerey polarized $\bar{p}$ and $p$ beans required in this study are currentiy in proposnl at Fivil and ClMUT. 


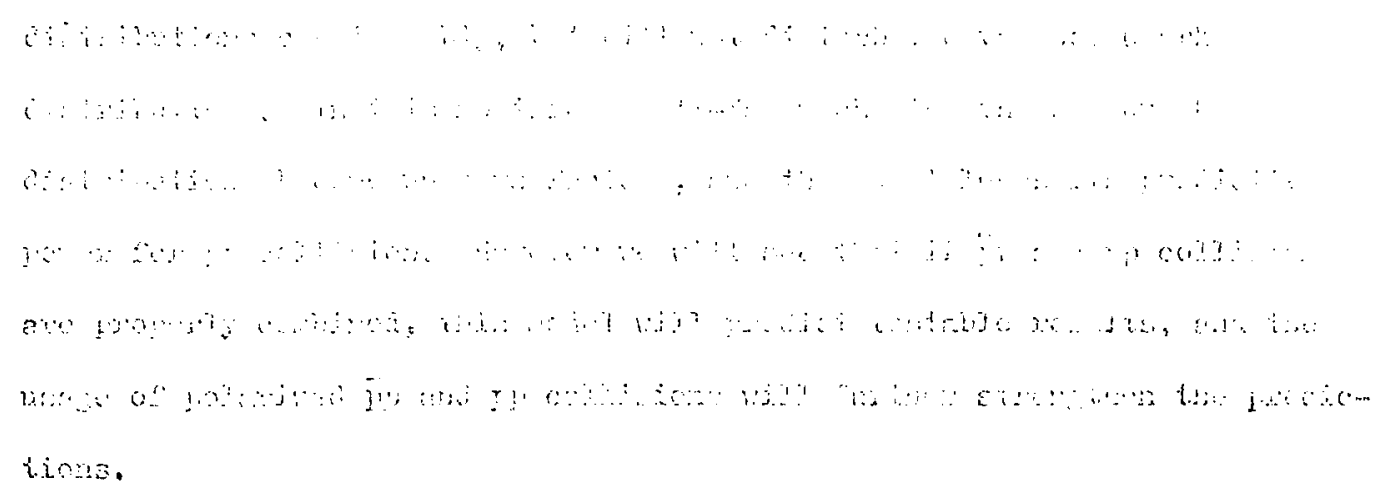

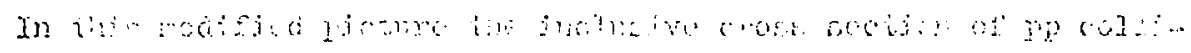

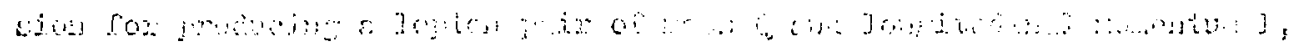

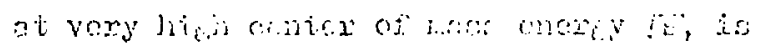

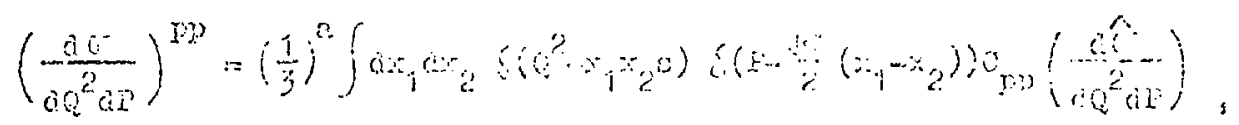

wit!

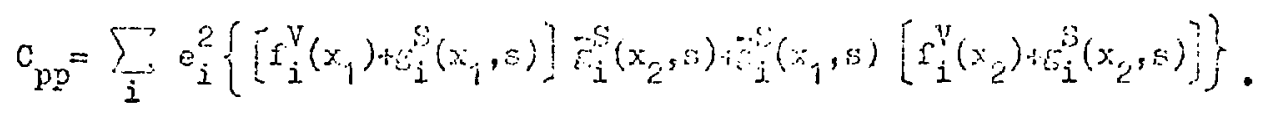

Here $x_{1}$ and $x_{2}$ are fuactions of the incident longitudinel monentiat cerricd by the partons $i, c_{i}$ are their changes, and $f_{i}^{V}(x)$ and $\varepsilon_{i}^{S}(x, s)$ are the densities of the valence and the sea cuark-nartons respectively. The function $f_{i}^{S}(x)$ will represent the density of the sea quark-partons before been disturbed by the hadronic interactions. The bar over the density functions denotes the densities of antiquariss. The nomalization is such that for electro-production 


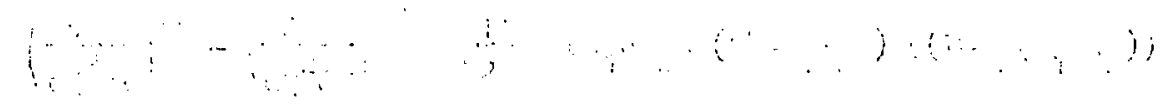

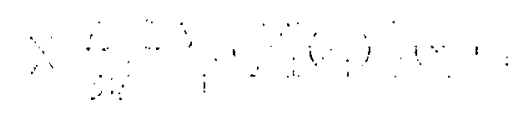

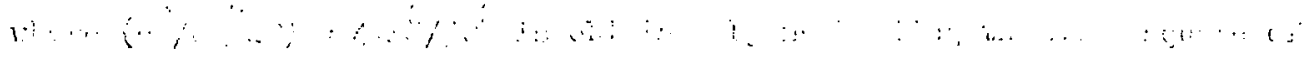

t.

(1)

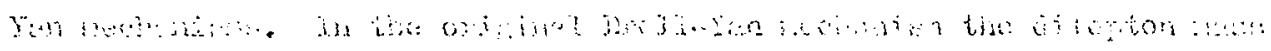

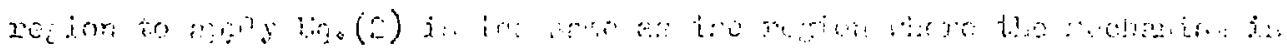

mpa

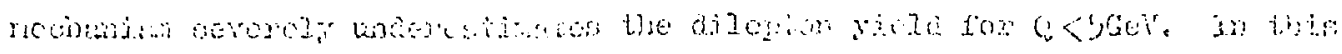

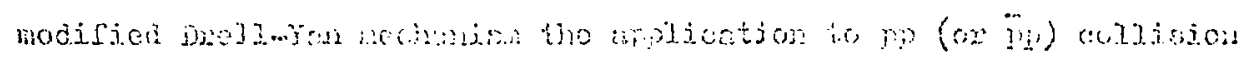

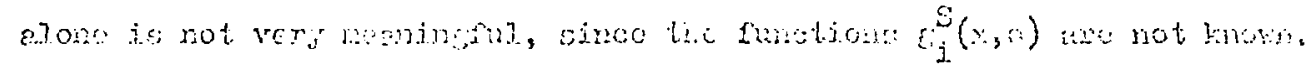

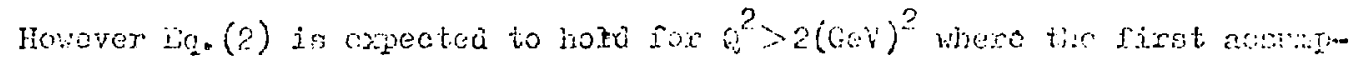

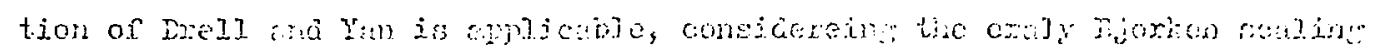

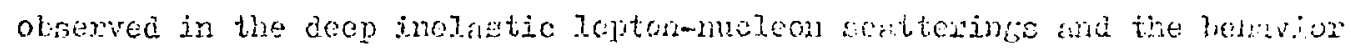

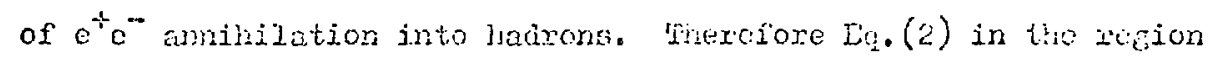

$Q^{2}>2(\mathrm{GeV})^{2}$ i.j.l1 provide a very important test of inis modificed Drell-ian

mechanion, since the density functions $f_{i}^{v}(x)$ are obtairntio, ir principlo,

from the dee? inelastic lepton-nucleon scatterine processes.

For the collision between two polarized protons, one with the splu $S_{1}=S$ and the other $S_{2}=+S, E q .(1)$ is replaced by

$$
\begin{aligned}
& \left(\frac{d U}{d Q^{2} d P d \delta}\right)_{S_{1} s_{2}}^{p p}=\left(\frac{1}{3}\right)^{2} \int d x_{1} d x_{2} \delta\left(Q^{2}-x_{1} x_{2} s\right) \delta\left(p-\frac{\sqrt{s}}{2}\left(x_{1}-x_{2}\right)\right)
\end{aligned}
$$

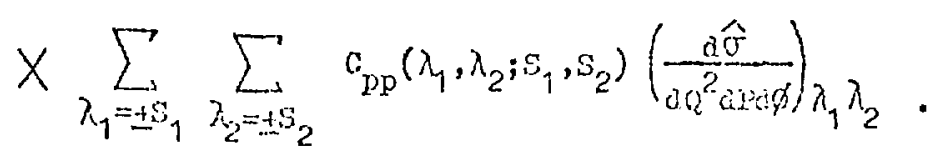




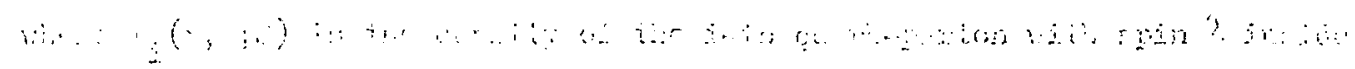

ан

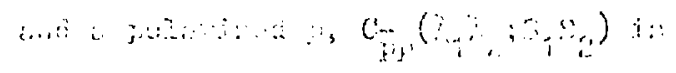

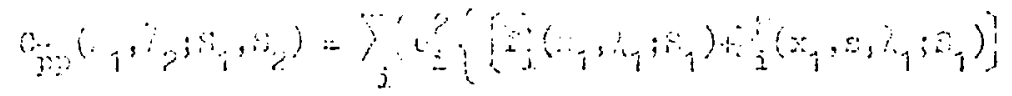

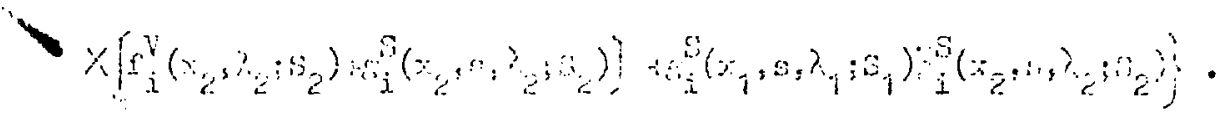

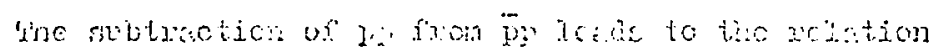

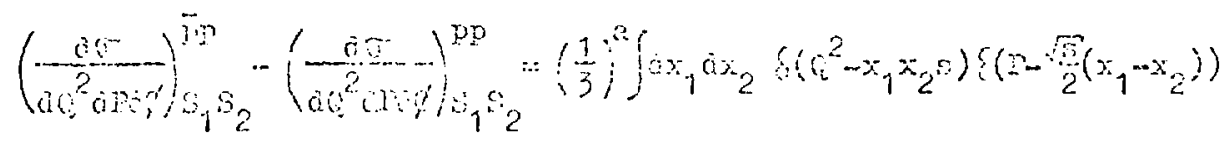

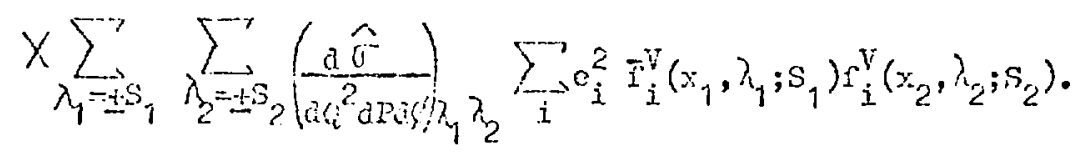

The cross grctions fox a polaxizcò quark-antiquark pair o annihilate into two leptons are

$$
\left(\frac{d \hat{\sigma}}{d \Omega^{2} a P Q \phi}\right)_{S_{1} S_{2}}=\frac{\alpha^{2}}{6 Q^{2}} \times \begin{cases}\left(1+2 \cos ^{2} \phi\right), & s_{1}=S_{2} \\ \left(3-2 \cos ^{2} \phi\right), & s_{1}=-S_{2}\end{cases}
$$

for trancversej.y polarized guarks, and 


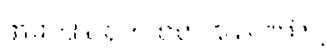

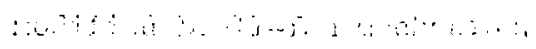

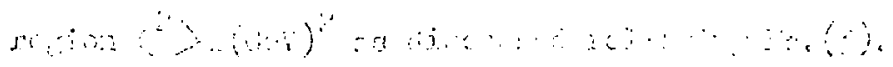

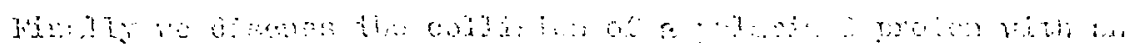

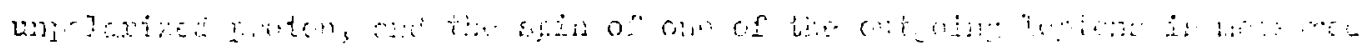

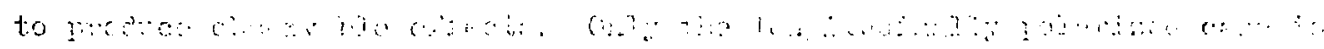

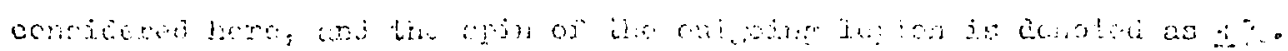
Me coser botion is

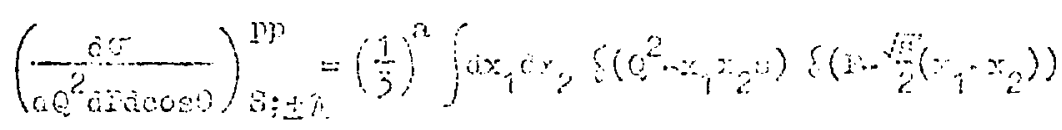

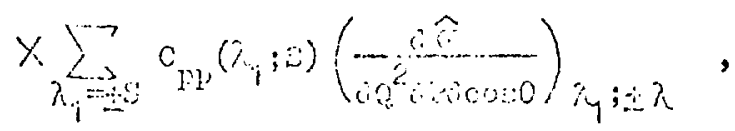

$\operatorname{arnd}$

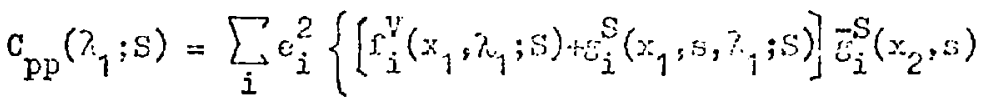

$$
\begin{aligned}
& \left.+\bar{G}_{i}^{S}\left(x_{1}, \lambda_{1} ; j\right)\left[f_{j}^{W}\left(x_{2}\right)+s_{i}^{S}\left(x_{2}, s\right)\right]\right\} \text {. }
\end{aligned}
$$

The quark-antiquark aninilation cross section $\left(d \hat{\theta} / \alpha \theta^{2} d r a \cos \theta\right) \lambda_{1} i \dot{i}$ at $P=0$ is $T \alpha^{2}(i+\cos \theta)^{2} / 8 \varepsilon^{2}$. Here $\theta$ is the scattering anele of the outroing lepton whose spin is measured. The cross section for $\bar{p} p$ collision can be written similasly, and the subtraction leads to 
$\therefore:$

$1 \div \quad \vdots \quad$

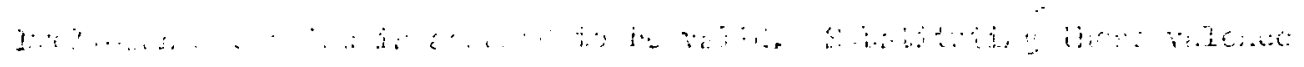

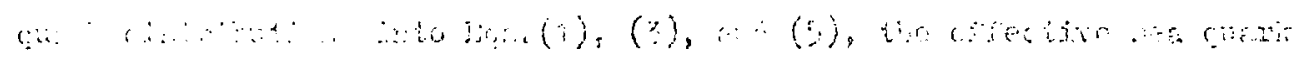

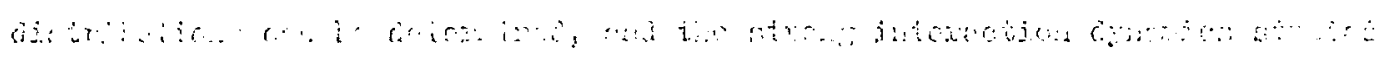
jow

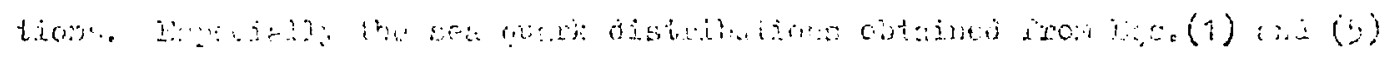

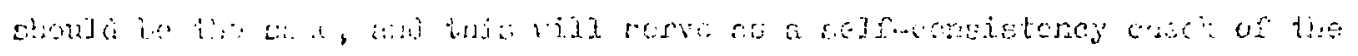

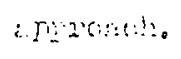

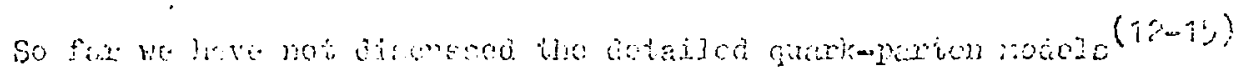

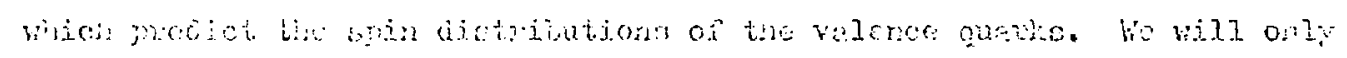

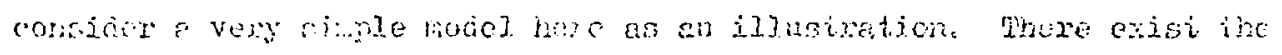

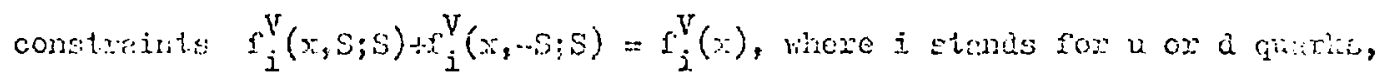

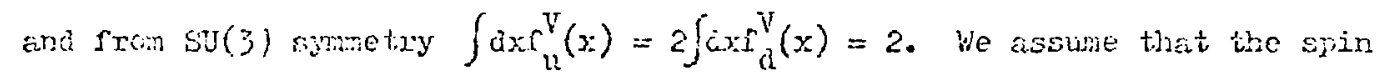
of the proton is wimply the sun of wise epin of the valence giarks. 'inis Jerde to the congtraint

$$
\int d x\left\{f_{u}^{V}(x, s ; s)-f_{u}^{V}(x,-s ; s)\right\}+\int d x\left\{r_{d}^{V}(x, s ; s)-f_{d}^{V}(x,-s ; s)\right\}=1 .
$$

The relation $f_{i}^{V}(x, s ; s)=a_{i} f_{i}^{V}(x)$ is furthex introduccd to complete this aimplc quark moicl. Substituting these relations into Eq. (7), and with the help of the constraints we obtain line relaition $a_{d}=2\left(1-a_{u}\right)$. 



$$
\begin{aligned}
& \therefore \\
& \vdots \\
& \vdots
\end{aligned}
$$

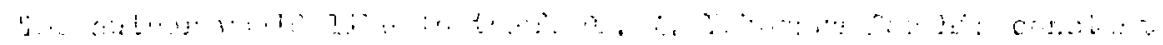

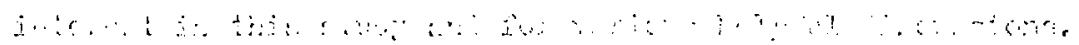




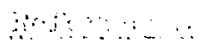

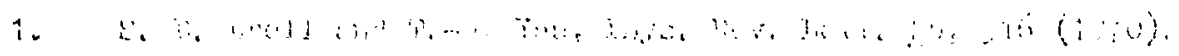

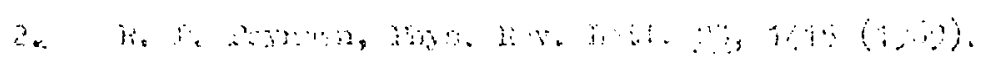

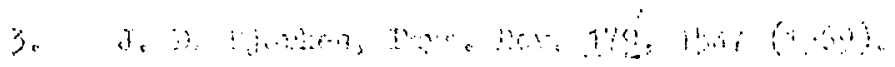

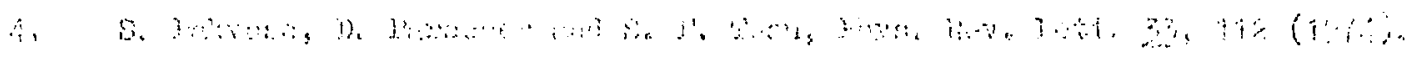

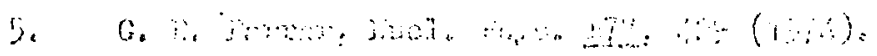

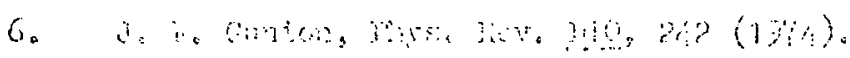

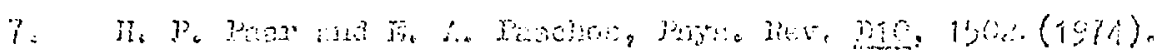

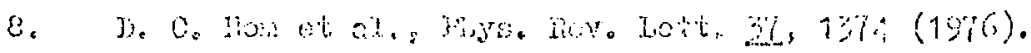

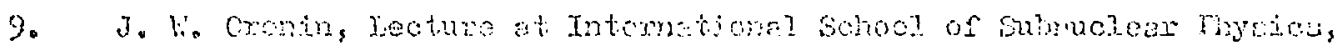
brice $(1976)$.

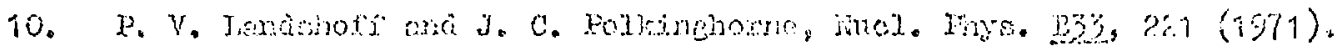

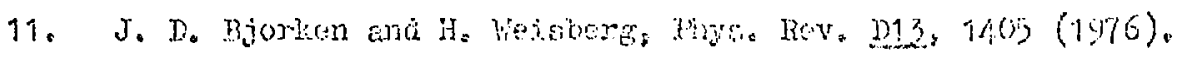

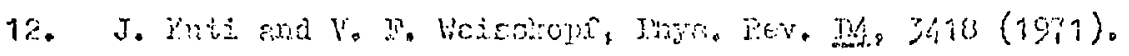

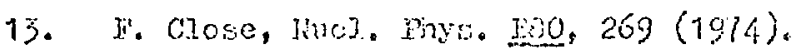

14. G. Donokos, S. Kovesi-Donokos, and F, Shombers, Fnos. Ror. I23, 1191 (1971).

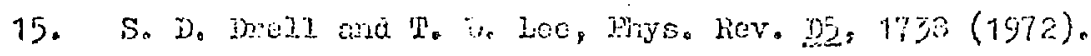

